\title{
Jornalismo das fontes: a profissionalização da comunicação nas organizações
}

\author{
Journalism sources: professionalization of communication \\ in organizations
}

\begin{abstract}
Aldo Antonio Schmitz
Jornalista, com mestrado em Jornalismo pela Universidade Federal de Santa Catarina (UFSC), Florianópolis, SC - Brasil, e-mail: aldoschmitz@gmail.com
\end{abstract}

\section{Resumo}

Este artigo aborda a apropriação dos processos e fundamentos do jornalismo pelas fontes de notícias, que trataram de profissionalizar a comunicação nas suas organizações para interferir estrategicamente no espaço público, a mídia. Utilizam técnicas refinadas de comunicação nas relações com os jornalistas. Fazem um planejamento apurado das interferências na mídia, incluindo a capacitação das fontes (mídia training). O objetivo é tratar dessas questões, desde as características da assessoria de imprensa contemporânea, suas ferramentas, a consolidação dos jornalistas nessa função, o treinamento das fontes e suas relações com o jornalismo, gestão de crises e mensuração de resultados. O trabalho conjuga esse fenômeno com uma pesquisa de opinião (survey), quantitativa, com 440 entrevistados, entre fontes de notícias, assessores de imprensa e jornalistas. Isso permite verificar e demonstrar as ações e estratégias das fontes, inclusive as equivocadas, em persuadir os jornalistas a reproduzir os fatos, os enfoques, as falas e os seus interesses.

Palavras-chave: Jornalismo. Comunicação nas organizações. Assessoria de imprensa. Profissionalização.

\section{Abstract}

This paper discusses the appropriation process and fundamentals of journalism news sources, who tried to professionalize communication in their organizations to intervene strategically in public space, the media. Using refined techniques of communication in relationships with journalists. They calculated planning of 
interference in the media, including the training of sources (media training). The goal is to address these issues, since the characteristics of contemporary press office, your tools, the consolidation of journalists in this role, the training of sources and its relations with journalism, crisis management and measurement of results. The work combines this phenomenon with a survey, quantitative, with 440 respondents, between news sources, press officers and journalists. This allows you to verify and demonstrate the actions and strategies of sources, including mistakes in persuading journalists to reproduce the facts, viewpoints, speeches and their interests.

Keywords: Journalis. Communication in organizations. Press offce. Professionalization.

\section{Introdução}

\section{O jornalismo é hoje uma profissão de passagem. Bernardo Kucinski}

O jornalismo não mais se restringe às redações da mídia tradicional. Assume uma nova dimensão, sendo também produzido por organizações não midiáticas e inclusive pelo público, atenuando a distinção entre o jornalista sagrado como mediador e seu novo papel, como articulador das informações. Karam (2010) indaga: "o jornalismo das 'redações', agravado pela sociedade da mídia com setores outros do processo produtivo, e com a hibridização do noticiário, estaria deixando a desejar?". A resposta levanta a hipótese de que:

as empresas não jornalísticas estejam produzindo melhor conteúdo e apresentação estética da informação e do conhecimento imediato, incorporando profissionais jornalistas, do que empresas jornalísticas, que poderiam estar se dirigindo ao hibridismo informação e publicidade como sobrevivência. Assim, jornalistas assessores poderiam, em última análise, produzir melhor conteúdo, com as características técnicas, teóricas e estéticas do jornalismo, do que os limitados pela pressão interna dos veículos da área (KARAM, 2010).

As estratégias das fontes presume a disseminação de informação jornalística tendo em vista os critérios éticos, estéticos e técnicos qualificados, para que seus conteúdos genuinamente jornalísticos sejam legítimos e credíveis. Com base em teorias e nesses pressupostos, o autor aplicou uma pesquisa de opinião (survey), quantitativa, com 440 entrevistados, sendo 71 fontes de notícias, 277 assessores de imprensa e 92 jornalistas de todo o Brasil. A pesquisa buscou recolher respostas, via perguntas fechadas, autoaplicáveis, pela internet, para verificar a validade das abordagens teóricas e comparar com pesquisas similares anteriores, conforme recomenda Novelli (2005).

\section{Assessoria de imprensa}

No início do século XX, a concentração de riqueza e o monopólio das grandes corporações dos EUA provocavam manifestações populares e críticas de jornalistas famosos como Mark Twain, bem como dos exploradores de escândalos (muckrakers), contra magnatas como John D. Rockfeller (mineração), John P. Morgan (banco) e William H. Vanderbilt (ferrovia). Pressionado, o governo americano impôs medidas para coibir os cartéis e trustes, o que exigiu das empresas e empresários explicações à opinião pública (WEY, 1986).

$\mathrm{Na}$ emergência do capitalismo selvagem, dominado por "barões ladrões" e "indústrias sem escrúpulos", entra em cena o jornalista Ivy Lee, vindo dos jornais New York Times e The World e da assessoria do candidato à presidência Alton Parker, derrotado por Theodore Roosevelt (mandato de 1901 a 1909). Em 1904, Lee é contratado pelo publicitário George Parker, com quem funda a agência pioneira de relações públicas, a Parker \& Lee, com o slogan "precisão, autenticidade e interesse” (HIEBERT, 1966; GURGEL, 1985). 
Enquanto colaborava com artigos nos jornais sobre as políticas selvagens e segregacionistas nos negócios, Lee defendia a transparência das corporações, dizendo "o público deve ser informado". E, quando a agência Parker \& Lee assumiu a "divulgação e propaganda" da companhia ferroviária Pennsylvania Railroad, em 1906, ele criou a "Declaração de princípios" da assessoria de imprensa, enviada em forma de carta aos editores (HIEBERT, 1966, p. 12):

Este nãoé um serviço de imprensa secreto. Todo nosso trabalho é feito às claras. Pretendemos divulgar notícias. Esta não é uma agência de propaganda. Se achar que o nosso assunto é matéria paga, não publique. Nossa matéria é exata. Informações adicionais sobre qualquer questão serão fornecidas prontamente e qualquer editor será auxiliado, com o máximo prazer, na verificação direta de qualquer declaração de fato. Em resumo, nosso plano é, com absoluta franqueza, divulgar à imprensa e ao público dos Estados Unidos, informações rápidas e precisas sobre assuntos de valor e interesse para o público, para o bem das empresas e das instituições públicas.

Esse documento é considerado um marco das relações públicas modernas, tendo Lee como seu fundador, embora alguns mencionem Edward Bernays como tal. Em 1908, com a agência dissolvida, ele continuou como executivo de comunicação da ferrovia até 1914, quando foi convocado por John D. Rockefeller Jr. para atuar como consultor da Standard Oil e "melhorar a imagem da família" após uma rebelião na mina de carvão em Colorado, conhecida como "massacre de Ludlow". Lee orientou Rockefeller a cooperar livremente nas investigações e "humanizar os negócios", enquanto adotava a filosofia "via de mão dupla", convencendo os jornalistas a não atacar e sim a publicar informações favoráveis aos grandes capitalistas (WEY, 1986).

Também aconselhava seus clientes a reciclar suas políticas empresariais e corrigir atitudes errôneas para criar uma opinião pública favorável e boa vontade da imprensa, embora tenha sido acusado de oferecer vantagens escusas aos jornalistas. Nisso, Lee viu uma excelente oportunidade de negócio e criou em 1916 outra agência, em sociedade com seu irmão James Lee Jr. e o empresário de jornal, W.W. Harris, a Lee, Lee \& Harris, que em 1919 se transformou em Ivy Lee \& Associados, atendendo ainda à siderúrgica Bethlehem Steel e à Chrysler (GURGEL, 1985; HIEBERT, 1966).

Antes das assessorias de imprensa, organizações públicas brasileiras costumavam pagar jetons ${ }^{1}$ aos repórteres, a quem forneciam informações, como forma de cooptação, "quer pela exclusividade do acesso, quer por favores e privilégios que, de forma mais ou menos explícita, completavam seus salários" (LAGE, 2001, p. 50), prática que vigorava deste o Estado Novo, do presidente Getúlio Vargas, que criou em 1939, o Departamento de Imprensa e Propaganda (DIP). O aparecimento das assessorias teve uma vertente moralizadora e ética, embora no início (ainda há casos) de duplo emprego nas redações e nas repartições públicas. A partir da década de 1960 as atividades de relações públicas e assessoria de imprensa, tal qual idealizada por Lee, chegam ao Brasil atreladas às indústrias e agências americanas de propaganda. O primeiro brasileiro a atuar nesta área foi José Rolim Valença, que começou a aprender a profissão na agência J.W. Thompson (KUNSCH, 1997).

Também nesse período, o escritor e jornalista Hernâni Donato, em São Paulo, na Standard Propaganda, e Evaldo Simas Pereira, no Rio de Janeiro, com passagem pelo Jornal do Brasil e Diário de Notícias, começaram a atuar na área, em agências de propaganda. Em 1962, Valença criou a AAB, primeira agência de comunicação do Brasil, tendo como sócio José Carlos Fonseca Ferreira, vindo da Ford. A pioneira treinava estagiários e dela originaram agências como ADS, em 1971, de Antonio De Salvo; a Inform, em 1975, de Carlos Eduardo Mestieri e Vera Giangrande, que depois criou com Flávio Schmidt a VG\&S, incorporada em 1994 à LVBA (KUNSCH, 1997). Segundo a Mega Brasil (2012) existem no país cerca de 1.500 agências, que

\footnotetext{
Gratificação pela presença e cobertura de seus eventos
} 
obtiveram receita de 2 bilhões de reais em 2011 e empregam cerca de 15 mil jornalistas formados.

Na década de 1970, até meados de 1980, a assessoria de imprensa era rotulada de "prostituição do jornalismo". No final dos anos 80 os sindicatos de jornalistas determinaram que as redações só podiam receber releases assinados por jornalistas e com o número do registro profissional, prática que se consolidou. Devido ao enxugamento das redações e ao grande número de formados em jornalismo, o mercado de trabalho nos meios de comunicação encolheu. Então, jornalistas consagrados como Audálio Dantas, Miguel Jorge, Júnia Nogueira de Sá, Carlos Brickman, Nemércio Nogueira, Sérgio Motta Mello e Marco Antonio Sabino, além dos recém-formados, começaram a migrar para a assessoria de imprensa em agências, organizações e de personalidades (KUNSCH, 2004, p. 14). Diante dessa realidade, Bernardo Kucinski (2005, p. 110) nota que o jornalismo tornou-se "uma profissão de passagem, da qual a maioria procura fugir logo que consegue emprego mais bem remunerado, menos estafante e menos controlado".

Atualmente a assessoria de imprensa é um dos compostos da comunicação nas organizações, ainda que se mantenha como o principal serviço, representando cerca de $45 \%$ da receita das agências de comunicação (ABRACOM, 2012), e não se restringe à produção e distribuição de releases, notas, artigos e sugestões de pauta, mas agrega outros procedimentos como a elaboração de políticas de comunicação e planos de divulgação, gestão das relações das fontes com a mídia, administração de crise, manutenção de salas de imprensa online, monitoramento de informação (clipping) associado à mensuração de resultado e à capacitação das fontes (mídia training), podendo acrescentar outras funções de comunicação, pois "passou a ser comum encontrar assessores de imprensa com ampla gama de atribuições, resultado da capacidade de reposicionar-se diante das novas exigências das organizações" (DUARTE, 2010, p. 71).

Essas atribuições incluem várias atividades capazes de estabelecer uma visão sistêmica das políticas e estratégias das relações de uma organização com seus públicos, que, segundo Henriques (2004, p. 25), vão da "comunicação digital e redes sociais e especialidades como a comunicação interna, estratégia de comunicação, branding e comunicação de marketing", além serviços sofisticados de comunicação (advocacy, lobby, public affair etc.) e de processos que envolvem as gestões da reputação organizacional, de eventos, de programas de responsabilidade social e ambiental e, principalmente, publicações empresariais, auditoria de imagem e estratégias de relacionamento com a mídia.

A assessoria de imprensa contemporânea, mesmo que o posicionamento seja operacional, evolui para um processo estratégico de gerar e gerir um vínculo durável com a mídia, por meio de ações contínuas, estruturadas e planejadas, não somente pelo simples fornecimento de informações ou atendimento à demanda dos jornalistas, mas na construção de um mosaico que leva a entabular diálogos e à formação de opinião favorável dos diversos públicos, para consolidar uma posição destacada no mercado e na sociedade. Isso exige "ser profissional na verdadeira acepção da palavra até porque ... a disputa é acirrada e só sendo "bom nisso' é que se pode triunfar na batalha da mídia" (BUENO, 2005, p. 62), que pressupõe prevenção e controle de crises, capacitação das fontes e mensuração de resultados.

Tanto esses propósitos como o perfil profissional são requisitos para que uma organização mantenha um bom relacionamento com diferentes veículos de comunicação, tendo acesso ao espaço editorial, onde constrói uma imagem positiva e mantém um repositório de reputação. Assim, mesmo que a pauta não seja favorável, quem mantém uma relação transparente e constante com a mídia consegue o seu espaço de defesa, amenizando os impactos negativos perante a opinião pública. Estrategicamente uma assessoria de imprensa reproduz em suas atividades os principais valores e fundamentos do jornalismo, zelando permanentemente pela verdade e pela fidelidade aos fatos, além de responder com agilidade e prover os jornalistas com informações confiáveis e relevantes (DUARTE, 2010).

Mas, qual a visão que os assessores de imprensa têm deles? A nossa pesquisa de campo pode esclarecer sobre as contribuições ou não dos profissionais em assessoria de comunicação no atendimento às necessidades das fontes nas suas estratégias de interferência na mídia. O papel estratégico da comunicação, por conseguinte da assessoria de imprensa, é contribuir para a 
melhoria da imagem e reputação da organização. Mesmo que $99 \%$ afirmem isso, algo idealizado, não significa que ocorra, pois a comunicação na maioria das empresas está longe de ser estratégica. Mas "a assessoria de imprensa deixou de ser uma ferramenta isolada, tática, e passou a ser uma ferramenta poderosa, estratégica, integrando-se aos esforços gerais e planejados de comunicação das organizações" (RIBEIRO; LORENZETTI, 2010, p. 240). Talvez nesse sentido, de vencer mitos e desafios, é que a pesquisa mostre elevados índices de que a assessoria de imprensa seja estratégica para a organização que assessora (91\%), contribua para o desempenho das fontes ( $94 \%$ ), favoreça que elas produzam e forneçam os fatos $(91 \%)$.

A ida dos jornalistas da mídia para a assessoria de imprensa tornou as fontes mais éticas e transparentes, como mostra a pesquisa (83\%), dotando a comunicação das organização de maior e melhor conteúdo, de transparência, de uma nova ética e de visão crítica. Essa situação vem provocando um efeito colateral na mídia, quando se antecipa às rotinas e práticas jornalísticas, para $89 \%$ dos entrevistados. Assim, promove-se a comodidade dos jornalistas (61\%), que publicam parcialmente ou na íntegra os releases (88\%). Esse fenômeno também é creditado à falta de investimentos nas redações, pois a atual cobertura jornalística, com raras exceções, aproveita os materiais das fontes. Percebe-se que não há mais a cultura de ouvir fontes antagônicas para confrontar os discursos.

\section{Capacitação das fontes}

Para melhor interagir com a mídia, executivos, políticos e personalidades, principalmente, cada vez mais participam de um treinamento, denominado mídia training, com o propósito de criar e manter uma interface positiva, notadamente em momentos de crise, pois "os jornalistas reúnem hoje em suas mãos os papéis de promotor, júri e carrasco", observa Nogueira (1999, p. 42), alertando os empresários para que se previnam contra o jornalismo investigativo, a síndrome das más notícias, o despreparo dos repórteres na cobertura do mundo dos negócios, a proliferação e a globalização de novas mídias. Aliás, as empresas que promovem os mídia trainings se valem desse discurso para convencer as organizações da sua realização, como justifica o diretor de uma agência especializada nesse tipo de treinamento, a RP Consult, Nemércio Nogueira (2007, p. 15):

Ao negligenciar essa necessidade de interação, a empresa não só se arrisca a perder visibilidade para a concorrência, como também deixa ao sabor dos veículos a versão dos fatos que constituem notícias, à revelia do seu interesse imediato em divulgá-los (para se promover) e explicá-los (para se defender).

Diante do dilema de serem atazanadas ou interferir na imprensa, sendo, "hoje, fonte para uma matéria e, amanhã, assumir a posição de porta-voz na condução de uma crise" (LUCAS, 2007, p. 13), as fontes procuram nos mídia trainings uma forma de se preparar para um relacionamento produtivo e de resultado, utilizando a mídia para disseminar informações, legitimar seus discursos, dialogar com seus públicos. Tanto quanto as fontes oficiais, também as empresariais e institucionais representam uma organização ou grupo social e não a si próprias, por isso essa capacitação ganha importância, por uma questão de segurança corporativa. Nesse treinamento, as fontes e os porta-vozes conhecem a estrutura, característica e a dinâmica de cada tipo de veículo de comunicação; as principais expectativas dos jornalistas, como agem e o que buscam; além de dicas práticas de relacionamento, postura e desempenho nas entrevistas (DUARTE; FARIA, 2010).

Essa capacitação não é um adestramento de fontes, mas, segundo Nogueira (1999, p. 43), visa "construir e manter um bom relacionamento com a mídia... e projetar uma boa imagem institucional", levando as fontes a perceberem que a divulgação é relevante para os negócios e não tem o objetivo direto e imediato de vender produtos e serviços (função da propaganda), embora ajude, mas de "contribuir para que sua organização obtenha o atributo de credibilidade... Ela ajuda a construir a admirabilidade da marca, porque tem grande influência sobre a opinião pública" (BARBEIRO, 2008, p. 13), enquanto para o jornalismo o que importa é a noticiabilidade (LAGE, 2001).

Para Chaparro (2001, p. 50), “a capacitação profissional das fontes também beneficia os processos jornalísticos". Disposta a verificar 
esse ponto de vista, Oliveira (2007) inquiriu vinte jornalistas de São Paulo e Rio de Janeiro. A sondagem aponta que 60\% aprovam a preparação das fontes, enquanto $65 \%$ acreditam que reduz a espontaneidade nas respostas e $70 \%$ percebem que o número de executivos treinados vem aumentando. Para 60\% dos jornalistas, a principal competência da fonte está na "clareza e objetividade", seguida de outros fatores: disponibilidade de dados, precisão das informações e conhecimento do assunto da entrevista, embora reclamem da insegurança e do medo dos executivos em conceder entrevistas, escondendo-se atrás dos releases.

Conforme a nossa pesquisa, cresce o número de fontes e porta-vozes que já participaram deste treinamento $(22 \%)$, sendo que a grande maioria participaria pela primeira vez ou novamente $(90 \%)$, pois acredita que isso melhorou ou aperfeiçoaria seu desempenho nas entrevistas (96\%). Poucos acham que o mídia training é utilizado somente nas crises $(8 \%)$. O caso da rede de hotéis Blue Tree ilustra bem essa estratégia. A partir de uma "política de fontes", que incluiu um mídia training aos gerentes e assessorias de imprensa regionais, "a rede ampliou em mais de 30\% sua participação na mídia e, o mais importante, tornou-se uma fonte respeitada e disponível para diferentes editorias" (MAIA, 2010, p. 28).

\section{A fonte escreve a notícia}

O principal instrumento das fontes nas relações com a mídia ainda continua sendo o release, que no início não passava de propaganda disfarçada, pois chegava às redações via departamento comercial dos jornais e atendia às vaidades dos anunciantes. Esse modelo prevaleceu durante os 20 anos do regime autoritário de governo no Brasil, a partir de 1964. Nessa época há uma proliferação de assessorias governamentais e "a busca da informação começa a inverter-se, ou seja, ao invés do repórter ir diretamente à fonte, as fontes, representadas pelos inúmeros press releases de assessorias, passaram a inundar as redações" (LIMA, 1985, p. 45).

Diferente, nos EUA e Europa o release apresenta-se como um complemento de informações, um roteiro sem os atributos de um texto jornalístico e distribuído durante as entrevistas para facilitar o trabalho dos repórteres. No caso brasileiro, principalmente a partir de meados da década de 1980, ele é redigido com todos os requintes de uma notícia, pronto para publicar, cabendo ao jornalista "checar a fonte, investigar o fato, descobrir o que há por trás daquela notícia e aí sim utilizá-lo como pauta ou mesmo publicá-lo", indica Lima (1985, p. 47). O autor observa que esse modelo de release é de grande valia aos meios de comunicação de pequeno e médio porte que não dispõem de estrutura para a produção do noticiário, lembrando que o governador do Paraná, Ney Braga, propôs acabar com os releases, em 1982, o que provocou uma revolta na imprensa local, obrigando-o a reverter a decisão.

Portanto, "mesmo sendo um instrumento de comunicação unidirecional, oficial, formal, vulgar, dependendo de seu conteúdo e circunstâncias de envio, pode ser muito bem-vindo em uma redação" (DUARTE, 2010, p. 309), que decide o seu aproveitamento ou não, em parte ou na íntegra. $\mathrm{O}$ veículo não informa ao público a origem (release) nem a autoria (assessor), embora alguns "jornalistas" assinam a matéria que não produziram. Isso porque, ao publicar o release, o jornalista e o veículo assumem e avalizam as suas informações. Em geral, a grande imprensa e a televisão consideram este material como uma sugestão de pauta.

Com a organização das fontes minimizaram-se algumas práticas nefastas na publicação de informações sobre empresas, produtos e serviços; a exemplo da pressão das agências de propaganda, conchavos e suborno de jornalistas, telefonemas à direção dos veículos e outras imposições comerciais. A presença de jornalistas dotou a assessoria de imprensa de maior e melhor conteúdo, transparência, de uma nova ética e de visão crítica. De outro lado, provocou a redução do jornalismo investigativo e uma acomodação nas redações, pois "o jornalista não vai às fontes. As fontes fazem chegar a ele o que lhes interessa divulgar. Bem mastigadinho" (KUCINSKI, 2002, p. 59).

\section{Assessor de imprensa é jornalista?}

Uma das pendengas no mercado de comunicação é definir se o profissional formado em jornalismo e que atua na assessoria de imprensa é 
ou não jornalista. Frequentemente esse tema polêmico suscita discussões. Uma corrente entende que jornalista é quem trabalha nas redações da mídia tradicional. Noblat (2003) vai além e provoca: "O que é, o que é? Formado em jornalismo, vive entre jornalistas, entrevista pessoas, apura, escreve e publica notícias, mas não é jornalista? É assessor de imprensa" e não tem autonomia para exercer um jornalismo "livre, crítico e, se necessário, impiedoso".

Além de polêmicas, essas questões geram contestações. Lopes Filho (2003) responde com outra inquirição: "será que existe autonomia necessária para se praticar jornalismo em algum canto do mundo?" Livre? O dia a dia de quem atua no jornalismo é cercado de ambiguidades e ideologias, o jornalista age conforme as determinações da organização (política editorial, manuais de redação, normas deontológicas etc.). Será que todo jornalista é ou precisa ser crítico e impiedoso? Em não sendo, deixa de ser jornalista, mesmo atuando em redações?

Quem acompanha Noblat (2003) argumenta que é da natureza do jornalismo ser investigativo e produzir notícias, geralmente, para o público consumidor de veículos comerciais. A Justiça Federal também foi envolvida nesse impasse, dizendo, em um momento, que "assessor de imprensa não exerce atividades típicas de jornalismo" (TST, 1998), e noutros, com base na lei de regulamentação da profissão de jornalista (BRASIL, 1969), reconhecendo como atividades privativas dos jornalistas a "coleta de notícias ou informações e seu preparo para a divulgação", o que é basicamente a atividade do assessor. Cornu (1998, p. 19) considera o jornalismo uma profissão aberta, por isso os seus contornos "permanecem ainda bastante imprecisos".

Lopes Filho (2003) e os defensores do assessor de imprensa jornalista apegam-se ao argumento de que os processos e procedimentos são praticamente os mesmos, embora atue como um articulador, em vez de mediador. Além de apurar e produzir as notícias de seu assessorado, faz outras tarefas. Os campos da comunicação e do jornalismo se confundem, uma vez que o diploma obtido nas faculdades de comunicação, habilitação em jornalismo, é registrado no Ministério do Trabalho, levando os diplomados a se autodefinirem "jornalistas", independentemente da função que exerçam.

Tanto na mídia como em organizações em geral, o jornalista tem uma delegação ou um compromisso com seu empregador. Por isso, Lage (2001, p. 70) considera que "assessores de imprensa são jornalistas, quando pensam e agem como jornalistas, não como marqueteiros". Distingue-se, portanto, na atitude de compromisso, "que é a essência da nossa profissão. O jornalista na assessoria, tanto quanto no jornal, é um intermediário" (LAGE, 2001, p. 69). Desse ponto de vista, a profissão não está delimitada ao espaço de trabalho, mas à técnica e à ética.

Essas questões geram inquietações, dúvidas e problemas no mercado de trabalho, segundo Chinem (2006, p. 53), que admite: "jornalista é jornalista em qualquer lugar e ponto final”. Para Chaparro (2001), a discussão fica empobrecida quando se despreza a contemporaneidade complexa do jornalismo, estabelecendo limites corporativistas. Mas, para o mercado e com o fim da exigência do diploma para o exercício da profissão, essa discussão faz pouco sentido. A Fenaj (2012), além de lutar pela restauração do diploma, defende a regulamentação da função de assessor de imprensa como atividade privativa dos jornalistas, bem como outras atribuições na comunicação das organizações. Mas Bucci (2010, p. A2) desconhece "países de boa tradição democrática onde jornalistas se vejam como assessores de imprensa ou vice-versa. Ambas as atividades são essenciais e dignas, por certo, mas distintas uma da outra".

Aliás, esse é um fenômeno brasileiro, onde a maioria dos jornalistas formados atua de um e de outro lado do "balcão" (jargão jornalístico), como arvora Caldas (2010, p. 331), "podemos estar momentaneamente, em diferentes lados do balcão. Entretanto, afinal, somos todos jornalistas". Mas isso não ocorre nos EUA e Europa, onde a assessoria de imprensa é entendida como uma atividade essencialmente de relações públicas e "incompatível com o jornalismo", afirmam Moutinho e Sousa (2010, p. 39). Em Portugal, por exemplo, o jornalista enquanto atua em assessoria de imprensa, suspende o seu registro, associando-se a outro sindicato, o de relações públicas, podendo, a qualquer momento, recuperar a credencial se retornar às redações.

Mas no Brasil, conforme a nossa pesquisa, para $83 \%$ dos assessores, o profissional formado em jornalismo e que atua em assessoria de imprensa é "jornalista" e defendem inclusive a regulamentação da profissão de assessor (75\%), como quer a Fenaj 
(2012). Ao contrário da maioria dos relações públicas, que entende a atividade como uma ferramenta de comunicação e não uma profissão; enquanto $45 \%$ consideram ser uma atribuição exclusiva dos jornalistas e não uma função típica dos relações públicas $(82 \%)$.

\section{Imagem e reputação}

As fontes aprimoraram suas estratégias. Contam com o assédio dos divulgadores, ávidos por "emplacar" suas pautas e buscar ações mais longevas no relacionamento com a mídia, atendendo às expectativas da imprensa em contar com fontes confiáveis, capazes de suprir suas necessidades. Em contrapartida, estabelecem um vínculo aos bons temas, para "reforçar o que chamamos de imagem institucional e criar condições favoráveis para seu nome, sua marca, seus produtos", construindo paulatinamente a sua credibilidade, explica Farias (2009, p. 92). Estrategicamente, as fontes desenvolvem "uma ação contínua, estruturada e planejada, visando não somente à mão única de fornecimento de informações" (FARIAS, 2009, p. 93), mas à crença de que a mídia contribui para a formação de opinião dos públicos prioritários (stakeholders) da organização.

Afinal, a volatilidade da opinião pública, em parte, está relacionada ao que a mídia veicula, favorável ou contrária, podendo levar uma organização à perda ou ganho de credibilidade. Por isso, as fontes entabulam diálogos e relações que incluem a mídia, desenvolvendo uma gestão de identidade, imagem e reputação, que, segundo Bueno (2009, p. 199), "sofrem de um processo de esvaziamento, certamente porque, utilizados às escâncaras, em qualquer situação e mesmo como sinônimos, acabam não significando coisa alguma". Por isso, carecem de um refinamento de seus conceitos ligados às ações das fontes em relação à mídia.

Bueno (2009, p. 200) observa que uma organização reflete imagens, que "são percepções que estão na cabeça dos públicos ou das pessoas individualmente, formadas pelo contato direto ou indireto com ela", ou seja, da organização como um todo, sustentada por diferentes segmentos de públicos. Almeida (2009, p. 228) concorda e complementa: "a formação da imagem é um processo subjetivo, único, relacionado à experiência individual e, ao mesmo tempo, somatório de sensações, percepções e interrelações de atores sociais". Preocupadas com essas percepções vacilantes, as fontes utilizam o espaço editorial da mídia, por ser polifônico, para manter uma imagem limpa e positiva, que a propaganda, por ser unilateral, não sustenta.

A imagem, opinião recente do público, difere da reputação por ser formada ao longo dos anos, tendo por base as ações e os comportamentos de uma organização. Trata-se de um crédito de confiança adquirido, associado ao bom nome, credibilidade e reconhecimento. Por isso, uma organização que desfruta de uma boa reputação, além de gerar notícias favoráveis, em momento de crise, se bem administrada, tem menor impacto na mídia e consequentemente no público. A maioria das organizações tem imagens, mas poucas chegam a ter uma reputação, porque esta é resultado de um processo mais demorado de interação. A gente pode dizer que a imagem é algo que se sente na pele e a reputação como algo que se sente na alma (BUENO, 2009, p. 200).

Mas as organizações empenham-se em formar uma identidade: como querem ser vistas, percebidas, ou seja, os atributos que as distinguem uma das outras, "o somatório de esforços, produtos, significados, valores, marcas etc., construídos ou produzidos" pela organização para o mercado e à sociedade, conjetura Bueno (2009). Mesmo que o público possa criar imagens e formar reputações, algumas organizações usam a mídia para firmar esses conceitos, outras impõem uma identidade idealizada, buscando ser o que realmente não são. Por exemplo, uma indústria tabagista proclamar-se socialmente responsável.

\section{Considerações finais}

Os jornalistas não criam autonomamente, dependem das fontes, e não admitem isso. As fontes, ao contrário, subvertem essa ordem. Em vez de somente serem pautadas, também pautam, contrapondo-se ao poder da mídia, produzindo conteúdos jornalísticos irrecusáveis. Nos seus intentos, usam estratégias para ter seus interesses e eventos selecionados e passar pelos portões (gates). Para isso, utilizam as técnicas e os procedimentos 
jornalísticos, como a objetividade. E não são isentas. Oferecem conteúdos "embalados" de interesse público. Apropriam-se dos processos, princípios e do saber do jornalismo, que antes eram privativos dos jornalistas nas redações.

Agem proativamente nas suas interferências no espaço público, a mídia. Elevam a comunicação com seus públicos ao patamar estratégico. Seus propósitos estão vinculados à valorização de sua imagem e na consolidação da boa reputação. Para buscar credibilidade e admirabilidade de seus públicos - a propaganda não basta, por ser unilateral -, as fontes encontram no jornalismo, por ser polifônico, um espaço para legitimar os seus discursos. $\mathrm{Na}$ pesquisa que realizamos, confirmam-se os pressupostos de que as fontes de notícias pautam em vez de serem pautadas, estabelecendo um diálogo com seus públicos e a sociedade para gerir a imagem e reputação suas ou de quem representam.

Por isso, as organizações profissionalizam a sua comunicação, que não mais somente produz e distribui releases, mas utiliza técnicas refinadas de comunicação nas relações com os jornalistas. Para cumprir com competência os seus propósitos, as fontes buscam capacitação e, preocupadas com as consequências do que dizem, tentam estabelecer condições nesse relacionamento, algumas reconhecidas pelos códigos de ética e deontológicos, mas outras não aceitas plenamente pelos jornalistas, que consideram equívocos.

\section{Referências}

ABRACOM - ASSOCIAÇÃO BRASILEIRA DE AGÊNCIAS DE COMUNICAÇÃO. Disponível em: <abracom.org.br>. Acesso em: 15 jun. 2012.

ALMEIDA, A. L. C. Identidade, imagem e reputação organizacional: conceitos e dimensões da práxis. In: KUNSCH, M. M. K. Comunicação organizacional: linguagem, gestão e perspectivas. São Paulo: Saraiva, 2009. v. 2. p. 215-242.

BARBEIRO, H. Mídia training: como usar a imprensa a seu favor. São Paulo: Saraiva, 2008.

BRASIL. Decreto-Lei n.o 972, de 17 de outubro de 1969. Dispõe sobre o exercício da profissão de jornalista. Diário Oficial da União, Brasília, p. 8931, 21 out. 1969.
BUCCI, E. Assessor de imprensa é jornalista? O Estado de S. Paulo, São Paulo, 9 set. 2010, p. A2.

BUENO, W. C. Comunicação empresarial no Brasil: uma leitura crítica. São Paulo: All Print, 2005.

BUENO, W. C. Comunicação empresarial: políticas e estratégias. São Paulo: Saraiva, 2009.

CALDAS, G. Relacionamento assessor de imprensa-jornalista: somos todos jornalistas! In:

DUARTE, J. (Org.). Assessoria de imprensa e relacionamento com a mídia: teoria e técnica. 3.ed. São Paulo: Atlas, 2010. p. 325-332.

CHAPARRO, M. C. Linguagem dos conflitos. Coimbra: Minerva, 2001.

CHINEM, R. Comunicação empresarial: teoria e o dia a dia das assessorias de comunicação. Vinhedo, SP: Horizonte, 2006.

CORNU,D. Ética da informação. Tradução de Laureano Pelegrin. Bauru: Edusc, 1998.

DUARTE, J. Assessoria de imprensa no Brasil. In: DUARTE, J. (Org.). Assessoria de imprensa e relacionamento com a mídia: teoria e técnica. 3.ed. São Paulo: Atlas, 2010. p. 307-332.

DUARTE, J.; FARIA, A. M. Media training: capacitando fontes e porta-vozes. In: DUARTE, J. (Org.). Assessoria de imprensa e relacionamento com a mídia: teoria e técnica. 3.ed. São Paulo: Atlas, 2010. p. 360-372.

FARIAS, L. A. Estratégias de relacionamento com a mídia. In: KUNSCH, M. M. K. Gestão estratégica em comunicação organizacional e relações públicas. São Paulo: Difusão, 2009. p. 91-104.

FENAJ - FEDERAÇÃO NACIONAL DOS JORNALISTAS. Disponível em: < fenaj.org.br $>$. Acesso em: 20 jun. 2012.

GURGEL, J. B. S. Cronologia da evolução histórica das relações públicas. Brasília: Linha, 1985.

HENRIQUES, M.S. (Org.). Comunicação e estratégias de mobilização social. Belo Horizonte: Autêntica, 2004.

HIEBERT, R. E. Courtier to the crowd: the life story of Ivy Lee, distinguished founder modern public relations. Ames: Iowa State University Press, 1966. 
KARAM, F. J. Pesquisas do Objethos: jornalismo e ciberespaço. Objethos: Observatório da Ética Jornalística, 15 jun. 2010. Disponível em:<objethos.wordpress.com>. Acesso em: 15 jun. 2010.

KUCINSKI, B. A pauta econômica e a agenda das assessorias de imprensa. In: DINES, A. (Org.). A mídia e os dilemas da transparência. Brasília: Banco do Brasil, 2002. p. 55-59.

KUCINSKI, B. Jornalismo na era virtual: ensaio sobre o colapso da razão ética. São Paulo: Unesp e Fundação Perseu Abramo, 2005.

KUNSCH,M.M.K. Relações públicas e modernidade: novos paradigmas na comunicação organizacional. 3.ed. São Paulo: Summus, 1997.

KUNSCH, M. M. K.Jornalismo e relações públicas: dos limites fronteiriços para uma ação integrada nas organizações. In: LOPES, B.; VIEIRA, R. F. Jornalismo e relações públicas: ação e reação, uma perspectiva conciliatória possível. Rio de Janeiro: Mauad, 2004. p. 10-15.

LAGE, N. A reportagem: teoria e técnica de entrevista e pesquisa jornalística. Rio de Janeiro: Record, 2001.

LIMA, G. M. Releasemania: uma contribuição para o estudo do press-release no Brasil. 2.ed. São Paulo: Summus, 1985.

LOPES FILHO, B. Assessor de imprensa é jornalista? Comunique-se, 21 jul. 2003. Disponível em: < comunique-se.com.br>. Acesso em: 12 abr. 2010.

LUCAS, L. (Org.). Media training: como agregar valor ao negócio melhorando a relação com a imprensa. São Paulo: Summus, 2007.

MAIA, Sandra. O negócio da comunicação: do conceito à ação. Rio de Janeiro: Qualitymark, 2010.

MEGA BRASIL. Anuário Brasileiro das Agências de Comunicação 2012. São Paulo, 2012.

MOUTINHO, A. V.;SOUSA, J.P. Assessoria de imprensa na Europa. In: DUARTE, J. (Org.). Assessoria de imprensa e relacionamento com a mídia: teoria e técnica. 3.ed. São Paulo: Atlas, 2010. p. 39-50.

NOBLAT, R. Assim é, se lhe parece. Comunicação Empresarial, São Paulo, n. 46, p. 2, 1.o trim. 2003.

NOGUEIRA, N. Media training: melhorando as relações da empresa com os jornalistas. São Paulo: Cultura, 1999.
NOGUEIRA, N. A prova dos dez: agregando valor a marcas e empresas pela divulgação jornalística. In: LUCAS, L. (Org.). Media training: como agregar valor ao negócio melhorando a relação com a imprensa. São Paulo: Summus, 2007. p. 15-38.

NOVELLI, A. L. R. Pesquisa de opinião. In: DUARTE, J.; BARROS, A. Métodos e técnicas de pesquisa em comunicação. São Paulo: Atlas, 2005. p. 164-179.

OLIVEIRA, J. O outro lado do media training. In: LUCAS, L. (Org.). Media training: como agregar valor ao negócio melhorando a relação com a imprensa. São Paulo: Summus, 2007. p. 155-190.

RIBEIRO, E.; LORENZETTI, G. Planejamento estratégico em assessoria de imprensa. In: DUARTE, J. (Org.). Assessoria de imprensa e relacionamento com a mídia: teoria e técnica. 3.ed. São Paulo: Atlas, 2010. p. 216-257.

TST - TRIBUNAL SUPERIOR DO TRABALHO. Assessor de imprensa: enquadramento como jornalista. Acórdão n.o 261412. Relator: Ministro Antônio Fábio Ribeiro, 3.a Turma, 15 maio 1998.

WEY, H. O processo de relações públicas. 3.ed. São Paulo: Summus, 1986.
Recebido: 20/09/2012

Received: 09/20/2012

Aprovado: 25/10/2012

Approved: 10/25/2012 